\title{
Polarimetric signatures of sea ice in the Greenland Sea
}

\author{
Skriver, Henning; Pedersen, Leif Toudal
}

Published in:

Proceedings of the International Geoscience and Remote Sensing Symposium

Link to article, DOI:

10.1109/IGARSS.1995.524028

Publication date:

1995

Document Version

Publisher's PDF, also known as Version of record

Link back to DTU Orbit

Citation (APA):

Skriver, H., \& Pedersen, L. T. (1995). Polarimetric signatures of sea ice in the Greenland Sea. In Proceedings of the International Geoscience and Remote Sensing Symposium: Quantitative Remote Sensing for Science and Applications (Vol. Volume 3, pp. 1792-1794). IEEE. https://doi.org/10.1109/IGARSS.1995.524028

\section{General rights}

Copyright and moral rights for the publications made accessible in the public portal are retained by the authors and/or other copyright owners and it is a condition of accessing publications that users recognise and abide by the legal requirements associated with these rights.

- Users may download and print one copy of any publication from the public portal for the purpose of private study or research.

- You may not further distribute the material or use it for any profit-making activity or commercial gain

- You may freely distribute the URL identifying the publication in the public portal 


\title{
Polarimetric Signatures of Sea Ice in the Greenland Sea
}

\author{
Henning Skriver and Leif Toudal Pedersen \\ Danish Center for Remote Sensing, Electromagnetics Institute \\ Technical University of Denmark, Building 348, DK-2800 Lyngby, Denmark \\ Phone: +45 458814 44, Fax: +45 45931634 , E-mail: hs@emi.dtu.dk
}

\begin{abstract}
Polarimetric SAR-data of sea ice have been acquired by the Danish polarimetric SAR (EMISAR ${ }^{1}$ ) during a mission at the Greenland Sea in August 19942. Video recordings from a low-altitude acquisition have been used for interpretation of the SAR data. Also, ERS-1 SAR data and NOAA AVHRR-data have been acquired. Microwave signatures of mulityear ice and open water have been studied, i.e. the backscatter coefficients for VV- and HV-polarizations, the co- and cross-polarized ratios, the correlations coefficients and phase difference have been computed as a function of incidence angle. The results correspond very well with previously reported results.
\end{abstract}

\section{INTRODUCTION}

A research and development project initiated in 1986 at the Electromagnetics Institute (EMI) of the Technical University of Denmark has resulted in a $\mathrm{C}$-band VV-polarized airborne SAR first flown in 1989 [1] and later a fully polarimetric system, which has successfully acquired data since 1993 [2]. The polarimetric extension of the system has been cosponsored by the EU's Joint Research Centre (JRC). An Lband system with full polarimetric capability was completed and tested early 1995 [3]. The Danish airborne polarimetric SAR (EMISAR) is used for scientific experiments conducted by the Danish Centre for Remote Sensing (DCRS) which was established early 1994 at EMI by the Danish National Research Foundation, and it is expected to be utilized by JRC for its European Airborne Remote Sensing Campaign (EARSEC). Also, EMISAR is used for the European Multisensor Airborne Campaign (EMAC) arranged by ESA.

The SAR system is installed on a Danish Air Force Gulfstream aircraft, and a significant amount of polarimetric SAR data have been acquired on various missions. The SAR system is normally operated from an altitude of approximately $13.000 \mathrm{~km}$, where the spatial resolution is 2 $\mathrm{m}$ by $2 \mathrm{~m}$, the ground range swath is approximately $12 \mathrm{~km}$ and typical angles of incidence range from $25^{\circ}$ to $55^{\circ}$. The processed data from this system are fully calibrated by using an internal calibration system supplemented by optional external calibration targets. The cross polarisation contamination is generally suppressed by more than $30 \mathrm{~dB}$.

The DCRS conducts research in collaboration with science partners within areas related to remote sensing techniques and Earth science, such as agriculture, environment, geology,

\footnotetext{
${ }^{1}$ Development of the EMISAR has been co-sponsored by the Thomas B. Thriges Foundation, the Danish Technical Research Council (STVF), the Royal Danish Air Force, the Technical University of Denmark, and the Joint Research Centre.

${ }^{2}$ The data acquisitions and data processing have been sponsored by the Danish National Research Foundation and the Danish Space Board.
}

0-7803-2567-2/95 \$4.00 @ 1995 IEEE glaciology, hydrology and sea ice. In the latter case the main subject is to study the microwave sea ice signatures and their variation with radar parameters, season and location. Two experiments have been carried out, a fall experiment in August 1994 and a winter experiment in March 1995. In the fall experiment EMISAR acquisitions were carried out together with video recordings for interpretation purposes. In the winter experiment this was supplemented by microwave radiometer and video acquisitions from a low-altitude aircraft. At both experiments ERS-1 SAR data and AVHRR-data from the NOAA satellites were acquired.

In this paper results from the fall experiment with C-band polarimetric SAR will be presented.

\section{DATA ACQUISITION}

During the sea ice fall mission in August 1994 SAR-data were acquired at more than $1000 \mathrm{~km}$ long strips with simultaneously video-recording partly covering the SARswath. Two strips were acquired, one during a flight at the nominal altitude of approximately $13.000 \mathrm{~km}$ going from south to north, and one at an altitude of approximately 3.500 $\mathrm{km}$ in an experimental mode going from north to south. At this low altitude the resulting ground range is approximately $10 \mathrm{~km}$ and the incidence angle ranges from $70^{\circ}$ to $80^{\circ}$. The two SAR-strips covered approximately the same area, and they were acquired within a 2 hours time interval. The flight lines were determined in such a way that the video-recording on the south-going low-altitude track was covering the SARswath of the high-altitude north-going SAR-swath, enabling a very detailed video-mapping of part of the SAR-swath. The EMISAR strips covered an area from approximately $80 \mathrm{~N}$, $18 \mathrm{~W}$ to $70 \mathrm{~N}, 2 \mathrm{~W}$. This is approximately in the middle of an ERS-1 acquisition from the previous day.

Ice conditions in the area were below average for this area in August, with floes of varying size drifting freely (forced by wind and current) towards the South. Weather observations of Kroyers Holme $\left(80.6^{\circ} \mathrm{N}\right)$ show temperatures around the freezing point throughout August, indicating that at $76^{\circ} \mathrm{N}$ temperatures were around the freezing point for most of the time.

The ice in the area was interpreted from the SAR and the video data to be multiyear ice floes with or without snow. The analysis in this paper has concentrated on a large ice floe that is also clearly seen in an ERS-1 frame. The floe is approximately $20 \mathrm{~km} \times 35 \mathrm{~km}$ and is drifting southwards with the East Greenland Current at a speed of approximately $100 \mathrm{~km}$ in 8 days (August 19-27). During those eight days the floe rotated approximately 140 degrees clockwise. 
The EMISAR mapping of the ice floe from high altitude is shown in Fig. 1. The bright areas are interpreted as snowcovered multiyear ice, whereas the somewhat darker triangle in the lower part of the floe is interpreted as multiyear ice with no snow cover as the area is also dark in the video image. From the image acquired at the low altitude the ridges in the ice floe are very clearly seen due to the shallow incidence.

The data have been studied in detail along the lines shown in Fig. 1. Line 1 consists entirely of snow-covered multiyear ice, line 2 and line 4 are composed to form an open water profile at the full incidence angle range, and line 3 is a mixture of open water at low incidence angles and multiyear ice with and without snow at higher incidence angles.

\section{SIGNATURES}

Various polarimetric parameters have been computed from the polarimetric data, as well as the backscatter coefficient $\sigma^{\circ}$. The parameters have been computed for the lines described in the previous section, and the estimation has been done based on areas of 100 by 100 pixels $(1.5 \mathrm{~m}$ pixel spacing) to reduce the influence of speckle. In Figs. 3 and 4 are shown the backscatter coefficient for VV and for $\mathrm{HV}$ polarizations, respectively, as a function of incidence angle. In Fig. 3 is also shown $\sigma^{\circ}$ derived frrom the ERS-1 image of the same ice floe. By extrapolation of the curve for the line 1 profile we can sce that the backscatter coefficients for the two SAR's correspond fairly well, with a slightly lower value for the EMISAR compared with ERS-1.

By comparing the angular response of the multiyear ice with results in [4], it is seen that the response in our case corresponds with the multiyear ice response for "late spring" in [4]. This indicates that the temperature is below the freezing point, so we get winter signature for the multiyear ice. The response for the open water corresponds well with open water signature for a few meters wind speed. As expected the cross-polarized signature is approximately $10 \mathrm{~dB}$ lower than the co-polarized signature, and it has weaker dependence with incidence angle than the co-polarized signature.

In Figs. 5 and 6 are shown the co-polarized ratio between $\mathrm{HH}$ and VV and the cross-polarized ratio between HV and $\mathrm{VV}$, respectively. The $\mathrm{HH} / \mathrm{VV}$ ratio for multiyear ice is close to 1 , which corresponds with the results in [5], where the ratio is slightly smaller than 1 . The cross-polarized ratio corresponds very well with the results reported in [5]. For the relatively smooth water surface the VV-polarization is larger than the HH-polarization, as expected. Also, the difference increases with increasing incidence angle, as the surface becomes smoother with increasing incidence angle.

The correlation coefficient between $\mathrm{HH}$ and VV is shown in Fig. 7. In [5] it is found that the correlation coefficient is decreasing at $\mathrm{C}$-band with increasing incidence angle when the scattering is dominated by surface scattering, and at an increasing rate in higher salinity ice. That corresponds well with the results shown in Fig. 7, where the multiyear ice curve is almost independent of incidence angle due to depolarization effects, and the curve for the open water decreases rapidly with incidence angle. The correlation coefficient for multiyear ice is slightly smaller than that found in [5].
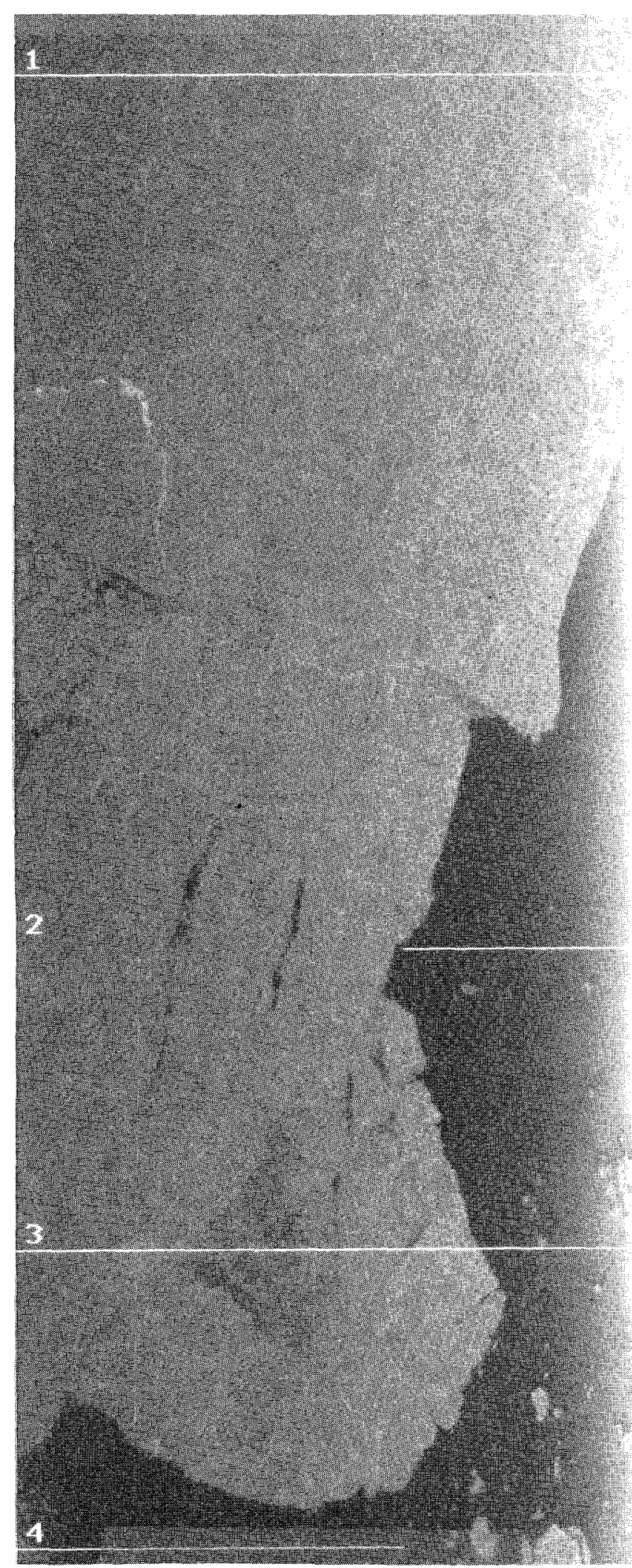

Fig. 1 EMISAR image (C-band, VV-polarisation) of the large multiyear ice floe. The incidence angls range from $25^{\circ}$ at the right side to $55^{\circ}$ at the left side of the image. 


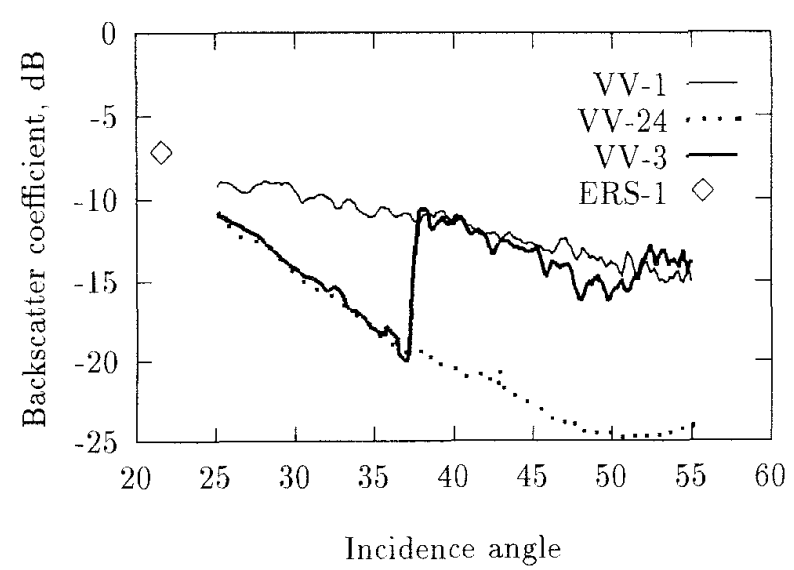

Fig. $3 \sigma^{\circ}$ backscatter coefficient for VV-polarization as a function of incidence angle

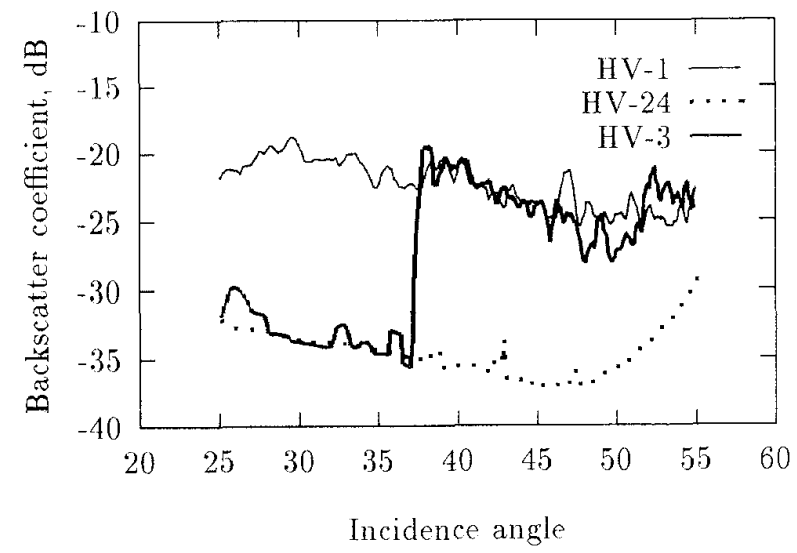

Fig. $4 \sigma^{\circ}$ backscatter coefficient for HV-polarization as a function of incidence angle

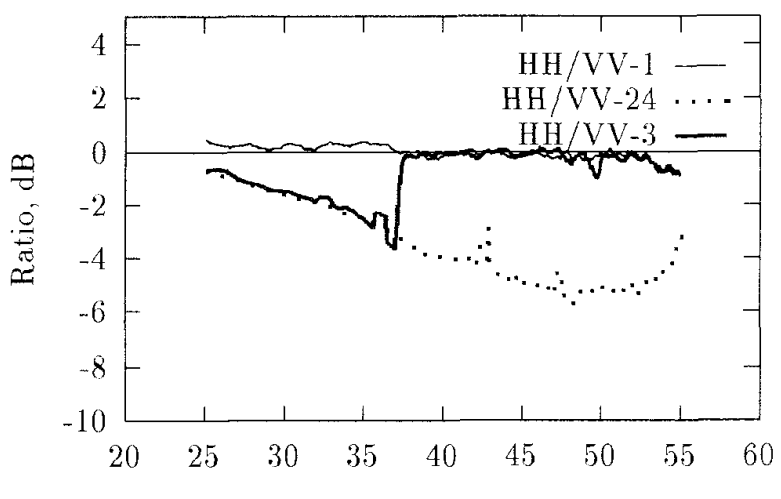

Incidence angle

Fig. 5 Co-polarized ratio between $\mathrm{HH}$ and VV.

The correlation between the $\mathrm{HH}$ and the HV-polarizations has also been computed, and it is rather low due to the azimuthally symmetric targets. Also, the phase difference between $\mathrm{HH}$ and VV has been computed, and it is between $0^{\circ}$ and $-2^{\circ}$ for multiyear ice. In [5] is also reported a mean phase difference of about zero, but with a large variance. This must be due to a very much smaller window size for the estimation of the phase difference, i.e. the individual 4-look pixels are used in [5].

The multiyear ice without snow (between $45^{\circ}$ and $50^{\circ}$ ) is not very clearly discriminated in any of the parameters.

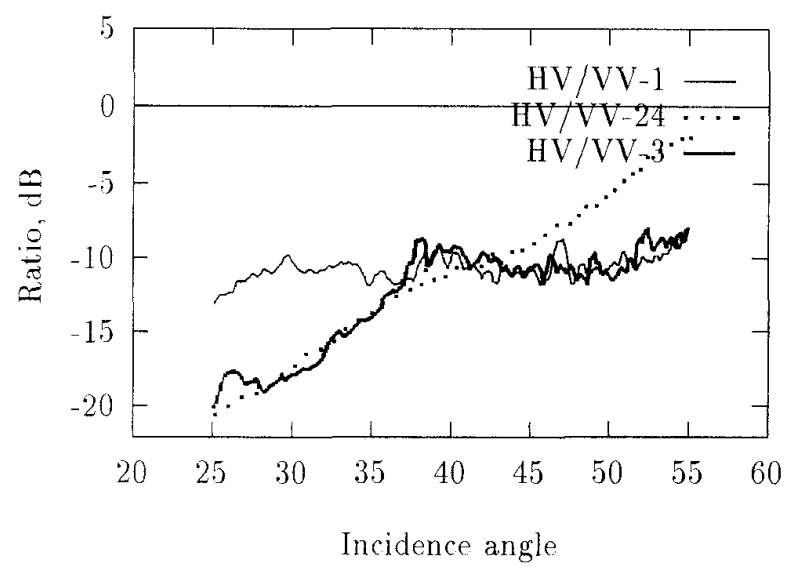

Fig. 6 Cross-polarized ratio between HV and VV.

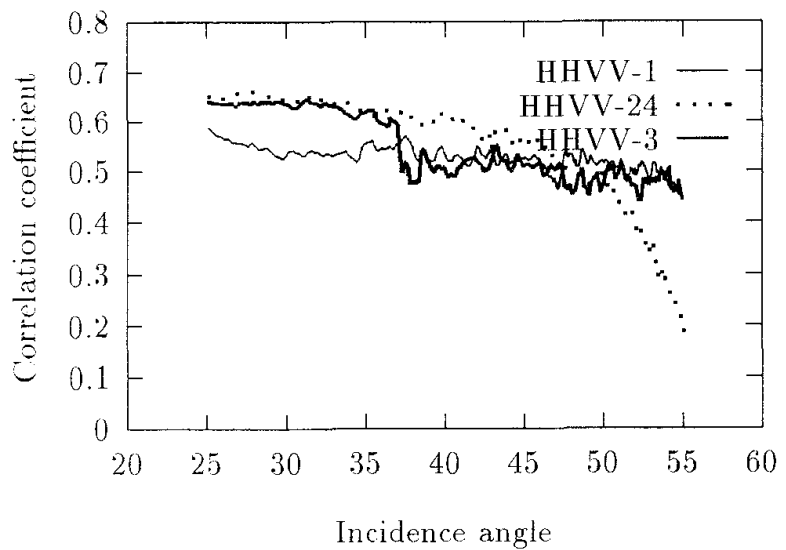

Fig. 7 Correlation coefficient between $\mathrm{HH}$ and VV.

\section{CONCLUSIONS}

EMISAR data have been acquired during a sea ice mission in August 1994, and microwave signatures for multiyear ice and open water as a function of incidence angle have been studied. The results obtained correspond very well with previously reported results for polarimetric SAR data of sea ice. The analysis will be continued using a more comprehensive data set acquired in March 1995 in the Greenland Sea.

\section{REFERENCES}

[1] Madsen, S.N., E. L. Christensen, N. Skou, and J. Dall, "The Danish SAR System: Design and Initial Tests", IEEE Trans. Geosc. Rem. Sens, vol. 29, 1991, pp. 417-476.

[2] Christensen, E. L., S.N. Madsen, J. Dall, N. Skou, K. Woelders, A. Netterstrøm, J.H. Jørgensen, J. Granholm, and M. Dich, "The Danish Polarimetric SAR for Remote Sensing Applications", Proc. IGARSS 1994, pp. 1361. 1364.

[3] Skou, N., J. Granholm, K. Woelders, J. Rohde, J. Dall, and E. L. Christensen, "A high Resolution Polarimetric LBand SAR - Design and First Results", this issue, 1995.

[4] Onstott, R. G., T. C. Grenfell, C. Mätzler, C. A. Luther, and E. A. Svandsen, "Evolution of Microwave Sea Ice Signatures During Early Summer and Midsummer in the Marginal Ice Zone", J. Geophys. Res., vol. 92, pp. 6825-6835, 1995.

[5] Drinkwater, M. R., R. Kwok, E. Rignot, H. Israelsson, R. G. Onstott, and D. P. Winebrenner, "Potential Applications of Polarimetry to the Classificatio of Sea Ice", inF. D. Carsey, "Microwave Remote Sensing of Sea Ice., Geophysical Monograph 68, American Geophysical Union, 1992. 